Review Articles

\title{
Insulin and Obesity
}

\author{
B. Jeanrenaud \\ Laboratoires de Recherches Médicales and Département de Médecine, Université de Genève, Geneva, Switzerland
}

Animal models with genetic or experimentally-produced obesity are numerous. The abnormalities reported in these models vary from one animal type to another $[1,2]$. However, whether rats or mice made obese by lesions of the ventromedial hypothalamus, or genetic obese rats or mice are considered, analogous pathological traits can be observed. Obesity, in man and in animals [1] is often associated with glucose intolerance. Such abnormal glucose handling is almost invariably accompanied by hyperinsulinaemia [3], a paradoxical situation that indicates the existence of a state of resistance to insulin. Obesity has been shown to be a progressive condition that comprises two main phases: an early one without insulin resistance, a later one in which insulin resistance is apparent. The overall changes observed in this syndrome are schematized by Figure 1.

\section{Early Phase of Obesity}

When considering the early phase of obesity, that is the actual accumulation of fat, two main organs must be discussed: the liver and adipose tissue (Figure 1).

Livers of various obese animals synthesize too much triglycerides and secrete too much of these as very low density lipoproteins (VLDL); they oxidize little fatty acid; the imbalance between lipid synthesis and lipid oxidation results in fat infiltration of the hepatic parenchyma; simultaneously hepatic glucose output is decreased [4-6]. The B cells of obese animals oversecrete insulin, but the hepatic clearance of insulin is decreased when the concentration of insulin in the portal vein is raised, so that more insulin reaches peripheral tissues, and hyperinsulinaemia ensues [7].

During this phase of the syndrome, adipose tissue of obese animals is characterized by enhanced in situ lipogenesis and enhanced capacity to take up circulating VLDL, with a resulting increase in the size of the triglyceride-overloaded adipocytes $[1,6,8,9]$.

Most of the abnormalities of liver and adipose tissue metabolism mentioned above can be ascribed to hyperinsulinaemia (the possible origin of which is discussed below) since, first, they can be reversed toward or to normal by decreasing circulating levels of insulin [1] and, second, their occurrence is concomitant with the development of the hyperinsulinaemia [10]. Thus, during the early phase of obesity, liver and adipose tissue are basically normal tissues that are simply overstimulated by insulin. The same seems to apply to muscle although, as summarized in Fig. 1, the evolution toward the "later" phase occurs very rapidly in this tissue [1]. At the early phase of obesity, hyperinsulinaemia is still moderate, receptor changes and insulin resistance (as described below) being slight or absent [11].

\section{Late Phase of Obesity}

At a later phase of the syndrome, the time of appearance of which varies from species to species, hyperinsulinaemia becomes much more pronounced. Moreover, a state of insulin resistance is now apparent $[1,10,11]$. In vivo, such an insulin resistant state can be best demonstrated by the failure of exogenously administered insulin to lower blood glucose [1]. In vitro, the resistant state is detected principally in skeletal muscle and adipose tissue (much less in the liver) and is evidenced by the partial or total failure of in vitro added insulin to influence glucose metabolism of these tissues.

When considering insulin resistance, it should be recalled that insulin receptors are continuously synthesized and degraded [12]. A variety of factors 
ANIMAL OBESITY SYNDROMES

\begin{tabular}{|c|c|c|c|c|}
\hline & EARLY ABNORMALITIES & & LATER ABN & RMALITIES \\
\hline (1) & Insulinemia 4 & tIRI & Insulinemia & $4 t$ \\
\hline (2) & $: N$ or $\downarrow$ & $1 G$ & Glucose & $t$ or 11 \\
\hline & R number : $N$ & tR & R number & $\downarrow$ or $\mathrm{H}$ \\
\hline
\end{tabular}

(4)
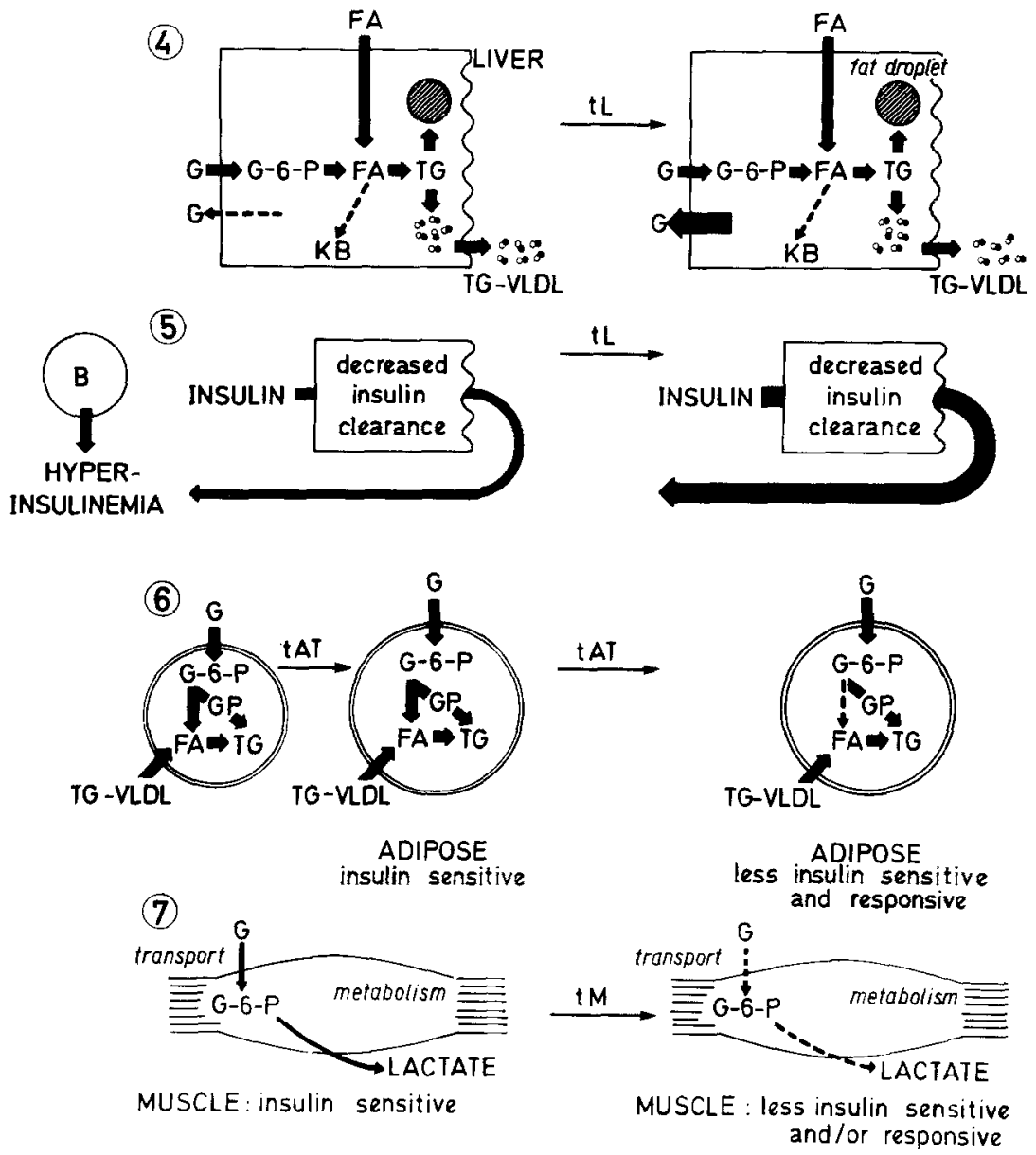

Fig. 1. Schematic representation of the progressive appearance of abnormalities in animal obesity syndromes. The duration $(t)$ needed to lead insulinemia (IRI), glycemia (G), insulin receptor number of target tissues (R), liver ( $\mathbf{L})$, adipose tissue (AT), and muscle (M) to their final pathological state is quite variable. Hyperinsulinaemia is one of the earliest abnormalities detected, and probably plays a major role in producing most of the abnormalities depicted here. Muscle is the tissue which evolves most rapidly toward an insulin resistant state. Ultimately, all metabolic pathways of glucose in muscle become less insulin sensitive and responsive (see text). Heavy arrows (except in 5) indicate pathways that are increased, dotted ones pathways that are decreased when compared to normal controls. $\mathrm{G}=$ Glucose; FA = Fatty acids; $\mathrm{KB}$ $=$ Ketone bodies; $\mathrm{TG}=$ Triglycerides; $\mathrm{VLDL}=$ very low density lipoproteins regulate the concentration of insulin receptors. The main one appears to be the insulin concentration itself. Thus, it has been shown that during exposure to insulin in vitro, the number of insulin receptors of cultured transformed lymphocytes [13] or cultured hepatocytes [14] decreases. This decrease is dependent on the duration of exposure to the hormone, in addition to its concentration. Moreover, insulin receptor number can be reversed to normal after removal of the hormone from the medium $[13,14]$. This 'so-called "down-regulation" of receptor number by increasing insulin concentrations and its disappearence upon removal of insulin are complex phenomena that seem to involve both degradation of the receptor upon binding of the hormone as well as receptor synthesis following insulin withdrawal [12]. It is noteworthy that the receptors "down-regulated" by the excess of insulin retain their normal physiological characteristics [12].

Due to the above considerations, it is of interest to observe that obese-hyperinsulinaemic animals, which have several similarities with obese humans, are characterized by a decrease in the number of the receptors in all target tissues, i. e., in liver [15], adipose tissue [16], and muscle [17]. Moreover, the decrease in receptor number is related to the degree of hyperinsulinaemia (see Figure 1) and returns toward or to normal when the hyperinsulinaemia of obese animals is corrected [1]. Thus, in obese animals, the "down-regulation" of insulin receptors and 
its reversal appear to be identical to that observed in the in vitro systems mentioned above.

Due to the observation of decreased insulin receptor number in obese animals, it was initially thought that this change was principally responsible for the overall insulin resistant state. However, the situation is more complex than originally anticipated and is not identical in all target tissues of insulin.

\section{Insulin Resistance in the Liver during Late Phase of Obesity}

The usual decrease in insulin receptor number occurs in hepatocytes of obese animals. However, because of the probable existence of "spare" receptors", enough insulin binding sites may remain available to permit continuation of the overstimulation of lipid synthesis pathways by hyperinsulinaemia, as found during the early phase of the syndrome (Fig. 1). Thus, these pathways do not become insulin resistant [1]. At this phase of the syndrome, the clearance of insulin by the liver is further reduced, thereby increasing peripheral hyperinsulinaemia [7]. There are some data available which suggest that livers now stop responding to an increased glucose load by a rapid decrease in gluconeogenesis and activation of glycogen synthesis [19], while the administration of small doses of insulin to obese humans fails to normally suppress hepatic glucose output as it does in normal non-obese individuals [20]. These observations suggest that insulin resistance may exist for at leastsome hepatic pathways that contribute to hyperglycaemia (Fig. 1).

\section{Insulin Resistance in Muscle \\ during Late Phase of Obesity}

The muscle mass is responsible for the largest part of glucose utilization in vivo. It is therefore of interest to investigate insulin resistance of this tissue in obese animal models, all the more as, for obvious practical reasons, muscle cannot be easily studied in humans. Insulin binding to skeletal muscles of obese animals is decreased when compared to lean controls $[21,22]$. With regard to this finding two remarks should be made: a) normal muscle has "spare" receptors; b) although the number of receptors in the muscle of obese animals is invariably decreased when compared to lean controls, its magnitude varies from species to species and is in the range of $20-30$ to $50-60 \%[21,22]$. As mentioned above, insulin

1 It should be recalled at this point that a tissue has "spare" receptors when the occupation of only a fraction of them by insulin is required to elicit full metabolic activation by the hormone [18]

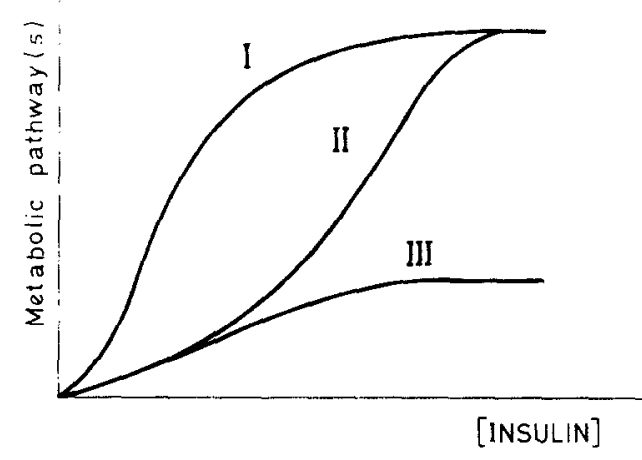

Fig. 2. Schematic representation of the relationship between insulin-stimulated pathways of glucose metabolism in muscle (similar data are obtained in adipose tissuc) and the concentrations of insulin added in vitro. Curve I: normal insulin response. Curve II: Shift to the right of the insulin dosc-response curve, with normal stimulation at supramaximal concentration of the hormone. This indicates decreased insulin sensitivity of the tissue. Curve III: Shift to the right of the insulin dose-response curve with, in addition, very poor stimulation even at supramaximal concentration of the hormone. This indicates decreased insulin sensitivity and responsiveness of the tissue

resistance was initially attributed primarily to decreased insulin binding. Subsequently, it was realized that such decreased insulin binding was not sufficient to explain the overall state of resistance, and that additional defects distal to the insulin receptor complexes had to exist. The emergence of such a more complex view of insulin resistance in obesity is based on many experiments schematized by Fig. 2 . Using this particular figure, two types of abnormalities of glucose metabolism are observed in muscles of obese animals: a) the presence of a shift to the right of the insulin dose response curve, although maximal stimulation can be elicited when supramaximal hormone concentrations are used (Fig. 2, Curve II), indicating the existence of a decreased sensitivity of muscle to insulin; b) the failure of even supramaximal concentrations of insulin to produce maximal metabolic stimulation (Figure 2, Curve III), demonstrating that a decreased responsiveness of muscle to the hormone is present $[21,22]$.

As with the overall obesity syndrome (Fig. 1), insulin resistance of muscles is a progressive phenomenon, the decrease in insulin sensitivity usually preceding that in insulin responsiveness. However, the rapidity of the evolution of the metabolic abnormalities may be such that the step of mere decrease in insulin sensitivity is missed, and only decreased insulin responsiveness is recorded [11, 21, 22]. It should be emphasized that even when insulin binding to muscles of obese animals is decreased by as much as $60 \%$, there are, theoretically, enough 


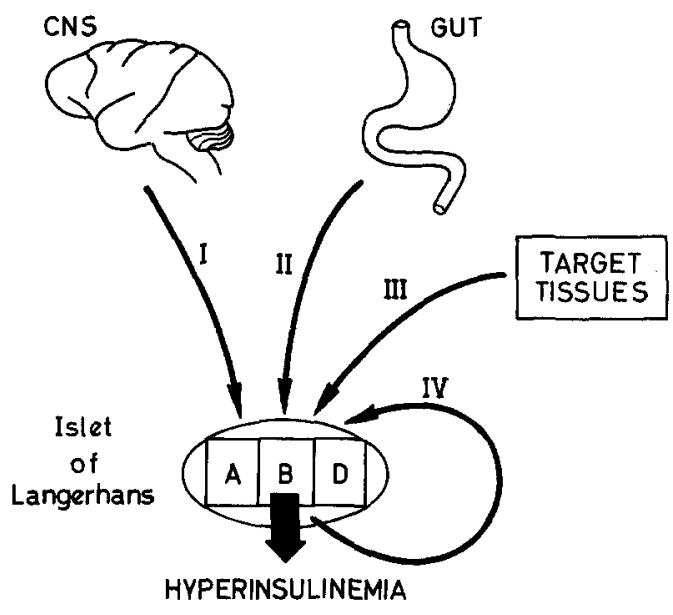

Fig. 3. Schematic representation of the possible causes of hyperinsulinaemia in obesity. I. Possible abnormal regulation of the islets of Langerhans by the CNS (e.g. hypothalamus) that ultimately favours hypersecretion of insulin by the B cells. Such abnormal regulation may implicate, under certain conditions, the $A$ (glucagon) and the D (somatostatin) cells as well, and be partly mediated by the vagus nerve. II. Possible abnormal regulation of the islets of Langerhans by the gut, c.g. via overproduction by the stomach and duodenum of GIP ("gastric inhibitory polypeptide"), an insulin secretagogue. III. Possible consequence of insulin resistance in target tissues which, via resulting hyperglycaemia, favours hypersecretion of insulin by the B cells. IV. Possible primary defect in the endocrine pancreas per se which, by unknown mechanisms, may favour hypersecretion of insulin by the B cells

remaining binding sites to permit a maximal insulin response, since the latter has been shown to occur at low occupancy of total available receptors ("spare" receptors). Thus, the following conclusions can be made: a) the functional consequence of decreased receptor numbers in skeletal muscle with "spare" receptors is only a decrease in their sensitivity to insulin (i. e. higher concentrations of the hormone are necessary to elicit biological effects equal to those of normal tissues); b) the decrease in insulin binding (i. e. the decreased insulin receptor number) cannot explain the decrease in maximal hormonal effects because such decreased binding does not exceed the proportion of "spare" receptors.

These considerations make it evident that some alteration(s) must occur beyond or apart from the insulin-receptor interaction and be responsible for the decreased insulin responsiveness. There are two obvious possibilities: a) an altered coupling between the insulin receptor complex and the effector system for one or several metabolic pathway(s) of glucose metabolism; b) intracellular abnormalities inhibitory to some pathways of glucose metabolism. Such intracellular defects have indeed been detected and may be multiple, as well as different from one target tissue to another $[22,23,24]$.

\section{Insulin Resistance in Adipose Tissue during Late Phase of Obesity}

Following the initial overstimulation by hyperinsulinaemia (with resulting fat accumulation) adipose tissue also progresses towards a state of insulin resistance [11, 23, 24], (Figure 1). The changes observed in this tissue have been particularly well studied in humans [23] and have many features in common with those previously described for muscle. In essence, insulin resistance in adipose tissue can be summarized as follows: As normal adipose tissue has "spare" receptors [24-26], it follows that the observed decreased insulin binding of adipocytes is responsible only for the observed decrease in insulin sensitivity (see Figure 2). The superimposed decrease in maximal response to maximal concentrations of insulin detected in large, triglyceride-overloaded fat cells, must also, as in muscle, be attributed to intracellular defects responsible for the observed decreased fatty acid synthesis despite a normal activation of the glucose transport system by insulin [23, 24]. This "adaptive" limitation of fatty acid synthesis does not appear to completely prevent excessive fat accumulation (Figure 1). Thus, VLDL uptake remains increased due to a persisting hyperinsulinaemia-mediated increase in lipoprotein lipase activity and glycerophosphate formation $[1,6,27]$.

\section{Possible Causes of Hyperinsulinaemia}

Hyperphagia and hyperinsulinaemia often occur in parallel in animal obesity syndromes, and one could hypothesize that hypersecretion of insulin is simply a consequence of hyperphagia. However, it has been shown that hyperinsulinaemia and obesity may develop independently from hyperphagia [28] and that hyperinsulinaemia is a major abnormality of both genetic or experimentally-produced animal obesity that ultimately contributes, as discussed above, to the establishment of insulin resistance [1].

Nevertheless, in obese humans as in animals, the primary cause of insulin over-secretion remains unknown, and the following possibilities can be proposed (Fig. 3): a) in obese humans, a primary insulin resistance in target tissues of insulin, with secondary hyperinsulinaemia and subsequent insulin resistance cannot be excluded. This possibility appears unlikely in animal models since hyperinsulinaemia is, if not the earliest, at least one of the earliest abnormalities detected $[1,10,29]$ and appears to be responsible for most of the metabolic changes described in Fig. 1. b) It has been suggested that genetically obese animals have several hypothalamic abnormalities [30-32]. Also, acute lesions of the ventromedial hypothalamic 
(VMH) area result, within minutes, in hyperinsulinaemia [33] that persists thereafter [4]. Recent experiments carried out in VMH-lesioned rats suggest that the CNS may modulate [33] the endocrine pancreas via the vagus nerve, although a factor, present in the lateral hypothalamus, could be another link between the CNS and the pancreas [34]. It has further been observed that hyperactivity of the vagus nerve that appears to follow lesions of the VMH area results in a reduced pancreatic somatostatin release together with an increase in both insulin and glucagon secretion $[35,36]$. Thus, the CNS (e.g. the hypothalamus) could partly regulate the $\mathrm{A}, \mathrm{B}$ and $\mathrm{D}$ cells of the pancreas and/or the inter-relationships between these cells, a regulation that could be abnormal in some types of obesity syndromes, thereby leading to hyperinsulinaemia. c) Hyperinsulinaemia of obese humans has been attributed to an overactivity of the entero-insular axis and, in particular, to an exaggerated release from stomach and duodenum, following glucose, fat and amino acid ingestion, of the so-called gastric inhibitory polypeptide (GIP), a factor that stimulates insulin release [37]. d) Finally, it has been proposed that the primary lesion leading to hyperinsulinaemia in some types of obesities may be in the endocrine pancreas per se [38].

To conclude, it is obvious that, for the time being, no clear origin can be proposed for hyperinsulinaemia of obesity syndromes. Furthermore, when discovered, it will probably vary from species to species and may ultimately prove to be a multifactorial and progressive abnormality that might differ in the early and late phases of the obesity syndrome, as is the case for insulin resistance [39].

Acknowledgements. This work has been supported by grant 3.1540.77 of the Swiss National Science Foundation, Berne (Switzerland), and the grant 1 R01 AM 25220-01 of the National Institute of Arthritis, Metabolic and Digestive Diseases, Bethesda, MD (USA).

\section{References}

1. Assimacopoulos-Jeannet, F., Jeanrenaud, B.: The hormonal and metabolic basis of experimental obesity. Clin. Endocrinol. Metab. 5, 337-365 (1976)

2. Bray, G. A.: The Zucker-fatty rat: a review. Fed. Proc. 36, 148-153 (1977)

3. Karam, J. H., Grodsky, G. M., Forsham, P. H.: Excessive insulin response to glucose in obese subjects as measured by immunochemical assay. Diabetes 12, 197-204 (1963)

4. Karakash, C., Hustvedt, B. E., Løvø, A., Le Marchand, Y., Jeanrenaud, B.: Consequences of ventromedial hypothalamic lesions on metabolism of perfused rat liver. Am. J. Physiol. 232, E286-E293 (1977)

5. Assimacopoulos-Jeannet, F., Singh, A., Le Marchand, Y., Loten, E. G., Jeanrenaud, B.: Abnormalities in lipogenesis and triglyceride secretion by perfused livers of obese- hyperglycaemic (ob/ob) mice: a relationship with hyperinsulinaemia. Diabetologia 10, 155-162 (1974)

6. Godbole, V., York, D. A.: Lipogenesis in situ in the genetically obese Zucker fatty rat (fa/fa): role of hyperphagia and hyperinsulinaemia. Diabetologia 14, 191-197 (1978)

7. Karakash, C., Assimacopoulos-Jeannet, F., Jeanrenaud, B.: An anomaly of insulin removal in perfused livers of obesehyperglycemic (ob/ob) mice. J. Clin. Invest. 57, 1117-1124 (1976)

8. Loten, E. G., Rabinovitch, A., Jeanrenaud, B.: In vivo studies on lipogenesis in obese hyperglycaemic (ob/ob) mice: possible role of hyperinsulinaemia. Diabetologia 10, 45-52 (1974)

9. Johnson, P. R., Hirsch, J.: Cellularity of adipose depots in six strains of genetically obese mice. J. Lipid Res. 13, 2-11 (1972)

10. Le Marchand-Brustel, Y., Jeanrenaud, B.: Pre- and postweaning studies on development of obesity in $\mathrm{mdb} / \mathrm{mdb}$ mice. Am. J. Physiol. 234, E568-E574 (1978)

11. Le Marchand, Y., Freychet, P., Jeanrenaud, B.: Longitudinal study on the establishment of insulin resistance in hypothalamic obese mice. Endocrinology 102, 74-85 (1978)

12. Kahn, C. R.: Membrane receptors for hormones and neurotransmitters. J. Cell Biol. 70, 261-286 (1976)

13. Gavin, J. R., Roth, J., Neville, Jr., D. M., De Meyts, P., Buell, D. N.: Insulin-dependent regulation of insulin receptor concentrations: a direct demonstration in cell culture. Proc. Natl. Acad. Sci. USA 71, 84-88 (1974)

14. Blackard, W. G., Guzelian, P. S., Small, M. E.: Down regulation of insulin receptors in primary cultures of adult rat hepatocytes in monolayer. Endocrinology 103, 548-553 (1978)

15. Kahn, C. R., Neville, Jr., D. M., Roth, J.: Insulin-receptor interaction in the obese-hyperglycemic mouse. J. Biol. Chem. 248, 244-250 (1973)

16. Freychet, P., Laudat, M. H., Laudat, P., Rosselin, G., Kahn, C. R., Gorden, P., Roth, J.: Impairment of insulin binding to the fat cell membrane in the obese hyperglycemic mouse. FEBS Lett. 25, 339-342 (1972)

17. Freychet, P., Forgue, E.: Insulin receptors in the heart muscle: Demonstration of specific binding sites and impairment of insulin binding to the plasma membrane of obese hyperglycemic mouse. Diabetes 24, 715-723 (1975)

18. Freychet, P.: Interactions of polypeptide hormones with cell membrane specific receptors: Studies with insulin and glucagon. Diabetologia 12, 83-100 (1976)

19. Kreutner, W., Springer, S. C., Sherwood, J. E.: Resistance of gluconeogenic and glycogenic pathways in obese-hyperglycemic mice. Am. J. Physiol. 228, 663-671 (1975)

20. Felig, P., Wahren, J., Hendler, R., Brundin, T.: Splanchnic glucose and amino acid metabolism in obesity. J. Clin. Invest. 53, 582-590 (1974)

21. Le Marchand-Brustel, Y., Jeanrenaud, B., Freychet, P.: Insulin binding and effects in isolated soleus muscle of lean and obese mice. Am. J. Physiol. 234, E348-E358 (1978)

22. Crettaz, M., Prentki, M., Zaninetti, D., Jeanrenaud, B.: Insulin resistance in soleus muscle from obese Zucker rats. Involvement of several defective sites. (Submitted for publication)

23. Olefsky, J. M.: Extrapancreatic factors: insulin resistance in obesity and diabetes mellitus. In: Diabetes mellitus, a pathophysiologic approach to clinical practise. Marliss, E. G., Assan, R., Girard, J. (eds.). Paris: Editions Flammarion (in press)

24. Czech, M. P., Richardson, D. K., Smith, C. J.: Biochemical basis of fat cell insulin resistance in obese rodents and man. Metabolism 26, 1057-1078 (1977)

25. Gliemann, J., Gammeltoft, S., Vinten, J.: Time course of insulin receptor binding and insulin-induced lipogenesis in isolated rat fat cells. J. Biol. Chem. 250, 3368-3374 (1975) 
26. Olefsky, J. M.: Effect of dexamethasone on insulin binding, glucose transport, and glucose oxidation of isolated rat adipocytes. J. Clin. Invest. 56, 1499-1508 (1975)

27. Koschinsky, Th., Gries, F. A., Herberg, L.: Regulation of glycerol kinase by insulin in isolated fat cells and liver of Bar Harbor obese mice. Diabetologia 7, 316-322 (1971)

28. Frohman, L. A., Bernardis, L. L., Schnatz, J. D., Burek, L.: Plasma insulin and triglyceride levels after hypothalamic lesions in weanling rats. Am. J. Physiol. 216, 1496-1501 (1969)

29. Coleman, D. L., Hummel, K. P.: Hyperinsulinemia in preweaning diabetes $(\mathrm{db})$ mice. Diabetologia 10, 607-610 (1974)

30. Coleman, D. L.: Obese and diabetes: Two mutant genes causing diabetes-obesity syndromes in mice. Diabetologia 14, 141-148 (1978)

31. Bereiter, D. A., Jeanrenaud, B.: Altered neuroanatomical organization in the central nervous system of the genetically obese (ob/ob) mouse. Brain Res. 165, 249-260 (1979)

32. Lorden, J. F., Oltmans, G. A.: Hypothalamic and pituitary catecholamine levels in genetically obese mice $(\mathrm{ob} / \mathrm{ob})$. Brain Res. 131, 162-166 (1977)

33. Berthoud, H.-R., Jeanrenaud, B.: Acute hyperinsulinemia and its reversal by vagotomy after lesions of the ventromedial hypothalamus in anesthetized rats. Endocrinology 105, 146-151 (1979)

34. Hill, D. E., Mayes, S., Di Battista, D., Lockhart-Ewart, R., Martin, J. M.: Hypothalamic regulation of insulin release in Rhesus monkeys. Diabetes 26, 726-731 (1977)
35. Rohner, F., Jeanrenaud, B.: Consequences of ventromedial hypothalamic lesions upon insulin and glucagon secretion by subsequently isolated perfused pancreases in the rat. (Submitted for publication)

36. Rohner, F., Jeanrenaud, B.: Arginine-induced insulin, glucagon and somatostatin secretion by isolated perfused pancreases from control and non-hyperphagic ventromedial hypothalamic lesioned rats. Effect of atropine. (Submitted for publication)

37. Creutzfeldt, W., Ebert, R., Willms, B., Frerichs, H., Brown, J. C.: Gastric inhibitory polypeptide (GIP) and insulin in obesity: Increased response to stimulation and defective feedback control of serum levels. Diabetologia 14, 15-24 (1978)

38. Strautz, R. L.: Studies of hereditary-obese mice (ob/ob) after implantation of pancreatic islets in millipore filter capsules. Diabetologia 6, 306-312 (1970)

39. Bray, G. (edt.): Recent advances in obesity research, II. Proc. of the 2nd International Congress on Obesity. Newman Publishing Ltd. 1978

Prof. B. Jeanrenaud

Laboratoires de Recherches Médicales

Université de Genève

64, Avenue de la Roseraie

$\mathrm{CH}-1205$ Geneva

Switzerland 